\title{
Prevalence and incidence of carpal tunnel syndrome in a meat packing plant
}

\author{
Ron G Gorsche, J Preston Wiley, Ralph F Renger, Rollin F Brant, Tara Y Gemer, \\ Treny M Sasyniuk
}

Departments of Community Health Sciences and Family Medicine, Faculty of Medicine

R G Gorsche

The University of Calgary Sport Medicine Center, Faculty of Kinesiology

J P Wiley

T Y Gemer

T M Sasyniuk

Department of Community Health Science, Faculty of Medicine, University of Calgary, AB, Canada

R F Brant

Arizona Prevention Center, College of Medicine, University of Arizona, AZ, USA R F Renger

Correspondence to: Dr Ron Gorsche, The University of Calgary Sport Medicine Center, 2500 University Drive NW, Calgary, AB T2N $1 \mathrm{~N} 4$, Canada

Accepted 18 December 1998

\begin{abstract}
Objectives-To determine prevalence and incidence of carpal tunnel syndrome (CTS) in a modern meat packing plant. The secondary objective was to explore the relation between ethnicity and CTS.

Methods-Six hundred and sixty five workers were interviewed and examined to find the prevalence of CTS. Subsequently, 421 workers without CTS were followed up and examined at a median interval of 253 days; of those, 333 remained without CTS and were again examined at a median interval of 148 days. Results-The prevalence and incidence of CTS was $21 \%$ and $11 / 100$ person-years, respectively. The incidence for Asian mixed, white, and other ethnicities was $12.0,12.2$, and 7.2 cases $/ 100$ person-years, respectively. The observed incidence for men and women was 9.7 and 18.4 cases $/ 100$ person-years, respectively. This difference was not quite significant $(p=0.068)$ with an estimated relative risk (women $v$ men) of 1.9 (95\% confidence interval $(95 \% \mathrm{CI}) 0.9$ to 3.8). The interaction between sex and use of tools was significant $(p=0.04)$, however, although the relative risk for CTS in women who used tools was 4.2 the numbers were small and not significant. The relative risk for men who used tools was 0.64 and not significant. The percentage of incident cases with comorbid disease was only $6.3 \%(3 / 47)$.

Conclusions-The prevalence and incidence of CTS in this workforce were higher than in the general population. However, the prevalence of CTS in this modern, mechanised plant was not significantly different from that reported in older plants. No relation was found between ethnicity, age, body mass index, and CTS for either prevalence or incidence. Comorbid disease among the cases of CTS is significantly less than that found in other industry.

(Occup Environ Med 1999;56:417-422)
\end{abstract}

Keywords: carpal tunnel syndrome; meat packing plant; ethnicity

Carpal tunnel syndrome (CTS) is defined as a complex of symptoms resulting from compression of the median nerve at the carpal tunnel. ${ }^{1}$ Symptoms of median nerve compression include pain, numbness, or tingling on the anterior surface of the index, middle, or radial half of the ring finger. It is often associated with weakness of hand grip or nocturnal symptoms including hand or arm pain and numbness. Provocative physical examination techniques such as Tinel's sign, Phalen's sign, and a two point discrimination test have been used to support the diagnosis of this condition.

Median nerve entrapment is the pathological process that causes symptoms of CTS. It is best diagnosed by a nerve conduction study, which, if performed according to guidelines such as those suggested by the American Association of Electrophysiological Medicine (AAEM), is the accepted "gold standard" to confirm the diagnosis of CTS before surgical release. ${ }^{2}{ }^{3}$

The prevalence of undiagnosed CTS in the general population has been estimated by de Krom et al at $5 \%$ for women and only $0.6 \%$ for men. ${ }^{4}$ Stevens et al reported an incidence of CTS of 99 cases per 100000 person-years in a retrospective Minnesota study that reviewed medical records. ${ }^{5}$ Rossignol et al reported the surgical incidence of CTS at 0.9 cases per 1000 adults in Montreal. ${ }^{6}$ Liss et al reported an increased surgical incidence for CTS compared with the general population of Ontario in an ice cream and popsicle manufacturing plant that employed between 48 and 101 workers over an 11 year period. ${ }^{7}$ The workers were not examined and surgical data were compiled from workers compensation time loss statistics and Ontario health plan total CTS hand release procedures.

The prevalence of CTS in the meat packing industry, the target population of the present study, has been reported to be $15 \%-24 \% .^{8-10}$ However, the previous plants studied were older, less mechanised, and multistoried. The meat packing industry has been identified as a high risk environment for all upper limb disorders. ${ }^{11}$ In a 1990 study, Novek compared two types of meat packing plants in Canada, one an older multistoried, low employee turnover, order specific plant and the other a modern, one story, mechanised, machine paced, high employee turnover, high productivity plant. ${ }^{12}$ Novek found a significant increase in time loss and injuries in the more modern and mechanised plant. $\mathrm{He}$ also concluded that as profit margins narrowed, wages failed to keep pace with the increased line speed and productivity quotas, generating an increase in labour unrest and subsequent turnover. Another possible explanation for the high turnover, not considered by Novek, might be an increase in the most disabling of the upper limb disorders, CTS, as the pace of the production line increased. 
The degree to which occupational hand use contributes to the development of CTS is controversial. ${ }^{13-15}$ Hand use alone is an insufficient exposure criterion for compensation in many European states. The European Commission Health and Safety Bulletin 1994, defines exposure criteria for CTS as: prolonged and repeated direct or indirect pressure on the median nerve at the wrist, or extreme movements of hyperflexion and hyperextension and worsened by vibrations. ${ }^{16}$ The United Kingdom Industrial Injuries Advisory Council accepts occupational CTS as a prescribed or compensatable disease only if the worker is exposed to a job involving the use of a hand held vibrating tool. ${ }^{17}$ Most United Kingdom consultants $(62 \%)$ surveyed in a recent study by Diwaker et al did not include CTS in their list of repetitive strain injuries. ${ }^{18}$ The Workers' Compensation Board of Alberta, Canada accepts CTS as a work related injury if most of the worker's duties involve repetitive grasping or the use of a tool in the affected hand.

Comorbid conditions, such as diabetes mellitus, rheumatoid arthritis, hyperthyroidism, and previous wrist surgery, are reported to occur in up to $20 \%$ of cases of CTS. ${ }^{19} 20$ Further, once thought to be rare, neurosyphilis has re-emerged masquerading as CTS in the workplace. ${ }^{21}$

Nathan et al studied the possible association of ethnicity and CTS by comparing Japanese and North American furniture assembly workers. $^{22}$ That study reported significantly less symptoms and fewer surgical procedures among the Japanese cohort, yet there were no significant group differences when median nerve conduction abnormalities were compared. No similar study has been reported comparing Asian and North American white workers employed in the same industrial plant and exposed to the same machine paced stressors and occupational hand tasks.

Conservative treatment in the form of job modifications, physiotherapy, night splints, nonsteroidal anti-inflammatory drugs (NSAIDS), and occasionally steroid injections usually begins with the first reported complaint of median nerve symptoms. Thus, CTS impacts on the worker, employer, and insurer regardless of electrophysiological results or surgery. In 1995, the Workers' Compensation Board of Alberta registered 739 CTS claims totaling \$4 207738.00 and resulting in a total of 32829 days lost. ${ }^{23}$ There was an increase of about $\$ 2900000.00$ and 14000 days lost respectively over figures reported in 1990. This increase occurred despite the proliferation of university ergonomic departments and consulting firms the efforts of which are aimed at ergonomic keyboards, improved workstations, and postural retraining. Increased awareness of this condition by both workers and healthcare practitioners could also explain the increased claims from the Workers' Compensation Board of Alberta in the past. Knowledge of an industry's incidence can help project the total potential CTS compensation cases that may arise directly out of employment.

The purpose of this study is to determine the prevalence and incidence of CTS in a modern, single story, mechanised meat packing plant employing a multicultural group of workers and further we wish to ascertain if an association exists between CTS and any ethnic group in this workforce.

\section{Methods}

SUBJECTS

Approval for this study was granted by the University of Calgary conjoint ethics committee. All participants signed an approved informed consent form. Upon request translated forms were available in the workers' native language. Nine hundred and fifteen workers at a meat packing plant, employed for more than 1 month, were invited to participate between October 1993 and June 1995. Six hundred and sixty five workers participated in the study, $23(3.5 \%)$ employees worked in supervisory and $32(4.8 \%)$ in clerical positions. The remaining $610(91.7 \%)$ employees performed tasks in separate production departments designed for skinning, sawing, gutting, trimming, bagging, boxing, and loading beef products. All jobs were repetitive and $76 \%$ of the workers used a hand held tool. One such typical job, clod puller, involves the constant, repetitive, forceful use of a knife in the dominant hand and a meat hook in the non-dominant hand for about 45 seconds in an attempt to remove the clod muscles from the chuck. This period of intense labour is followed by a rest period of 20 seconds that is spent sharpening the knife in preparation for the next of 241 clods pulled that day.

\section{PROCEDURES}

Initially, a cross sectional study was performed to determine point prevalence of CTS. Incidence was then determined when 421 workers who tested not to have CTS were followed up and examined at a median interval of 253 days; of those, 333 remained without CTS and were again examined at a median interval of 148 days. Data from the two intervals was combined to examine the relation between incidence and demographic characteristics. A case of carpal tunnel syndrome (CTS) was determined by satisfying criterion $\mathrm{A}$ and one component of criterion B as outlined in table 1 .

Criterion A was satisfied by a positive hand diagram for either pain or numbness. A positive response was recorded as pain or loss of sensation, involving at least one of either the thumb, index finger, or middle finger, starting after 1 month of employment and persisting for more than 1 week at the time of interview.

Criterion B was satisfied by a positive response to any one of the two examination tests. Tinel's test was considered positive if pain

Table 1 Definition of carpal tunnel syndrome: must satisfy both criteria

Criterion A:

A history of pain and numbness along the median nerve

distribution of the hand lasting more than 1 week at the time of examination

Criterion B:

A positive Tinel's sign or

a positive Phalen's sign 
Table 2 Demographic data

\begin{tabular}{|c|c|c|c|c|c|c|}
\hline & Total population & Men & Women & Asian mixed & White & Others \\
\hline \multicolumn{7}{|c|}{ Demographics of the prevalence study population: } \\
\hline Total (n (\%)) & $665(100)$ & $572(86)$ & $93(14)$ & $317(47.7)$ & $209(31.4)$ & $139(20.9)$ \\
\hline Mean (SD) age & $32.1(7.7)$ & $32.0(7.7)$ & $33.0(7.4)$ & $33.0(8.0)$ & $30.7(7.3)$ & $32.2(7.3)$ \\
\hline Mean (SD) height $(\mathrm{cm})$ & $169.8(9.9)$ & $171.6(9.1)$ & $159.2(7.5)$ & $164.4(7.1)$ & $176.8(9.1)$ & $172.0(9.1)$ \\
\hline Mean (SD) weight (kg) & $67.0(14.4)$ & $68.6(14.3)$ & $57.2(10.7)$ & $58.0(8.9)$ & $77.7(14.8)$ & $71.4(10.4)$ \\
\hline \multicolumn{7}{|c|}{ Demographics of interval 1 incidence study population: } \\
\hline Total $(\mathrm{n}(\%))$ & $421(100)$ & $357(85)$ & $64(15)$ & $207(49.2)$ & $117(27.8)$ & $97(23)$ \\
\hline Mean (SD) age & $32.5(7.7)$ & $32.4(7.8)$ & $33.2(7.2)$ & $33.5(7.9)$ & $31.0(7.6)$ & $32.3(7.3)$ \\
\hline Mean (SD) height $(\mathrm{cm})$ & $169.2(9.5)$ & $171.1(8.6)$ & $158.7(7.7)$ & $164.0(7.1)$ & $176.5(8.6)$ & $171.6(8.2)$ \\
\hline Mean (SD) weight (kg) & $65.6(12.8)$ & $67.4(12.5)$ & $55.7(9.6)$ & $57.9(9.0)$ & $75.0(12.8)$ & $70.6(9.3)$ \\
\hline \multicolumn{7}{|c|}{ Demographics of interval 2 incidence study population: } \\
\hline Total (n (\%)) & $333(100)$ & $282(85)$ & $51(15.0)$ & $166(49.8)$ & $90(27)$ & $77(23.2)$ \\
\hline Mean (SD) age & $32.7(7.8)$ & $32.7(7.9)$ & $33.0(7.2)$ & $33.5(8.0)$ & $30.8(7.5)$ & $33.0(7.4)$ \\
\hline Mean (SD) height $(\mathrm{cm})$ & $168.9(9.3)$ & $170.7(8.4)$ & $158.9(7.7)$ & $163.8(7.2)$ & $176.2(7.9)$ & $171.4(8.3)$ \\
\hline Mean (SD) weight (kg) & $65.4(12.8)$ & $67.2(12.6)$ & $55.5(9.0)$ & $57.8(9.2)$ & $74.6(12.7)$ & $71.1(9.1)$ \\
\hline
\end{tabular}

or paraesthesia was elicited or accentuated along at least one of the first three digits of the hand by allowing the flat end of a triangular reflex hammer to fall onto the distal wrist crease from the distance of one handle $(20 \mathrm{~cm})$ above the wrist. Phalen's test was considered positive if paraesthesias were elicited in the median nerve distribution when the subjects rested their elbows on a table with the forearms perpendicular to the surface and wrists flexed down and away from the body for a period of 60 seconds.

History was recorded by interview with a set questionnaire pertaining to demographics, and comorbid conditions such as rheumatoid arthritis, hypothyroidism, diabetes mellitus, alcoholism, pregnancy, and previous hand surgery. Type and position of hand held tool used, dominant hand, duration of employment, and job description within the plant were also recorded.

\section{STATISTICAL ANALYSIS}

Analysis of data was performed with the statistical program for social sciences (SPSS Version 6.0, Microsoft Corporation, Chicago, IL, USA) and S-Plus (v3.4, Mathsoft, StatSci Division, Seattle, WA, USA). The analyses of hand position used the Mantel-Haenzel test for linear association and the Pearson $\chi^{2}$ for significance. The two tailed $t$ test was used in the parametric analysis of variables found normally distributed - such as age and body mass index (BMI). Analysis relating to incidence was based on Poisson regression.

Data over the three examinations were used to calculate incidence. In the period between examinations 1 and 2, data from people who were did not have CTS at time 1 were considered. Follow up was calculated taking the specific elapsed time for each person, dividing by 2 for people positively diagnosed at examination 2 (to adjust for the time lag in diagnosis). In the second interval, similar calculations were applied to people without CTS at the second

Table 3 Descriptive prevalence and incidence results for carpal tunnel syndrome cases by ethnicity

\begin{tabular}{|c|c|c|c|c|}
\hline & \multicolumn{4}{|l|}{ Ethnicity } \\
\hline & Asian mixed & White & Other & Total \\
\hline Prevalence of cases $(n(\%)) p=0.43$ & $69 / 317(21.8)$ & $47 / 209(22.5)$ & $24 / 139(17.3)$ & $140 / 665(21)$ \\
\hline Incidence of cases (ppy) $\mathrm{p}=0.40$ & $26(12.0)$ & $14(12.2)$ & $7(7.2)$ & $47(11.0)$ \\
\hline
\end{tabular}

ppy=Incidence $/ 100$ person-years. examination. There was no evidence of a period effect; the incidence counts and follow up times were pooled to calculate relative risks.

\section{Results}

PREVALENCE STUDY

In total, 665 employees $(72.7 \%$ of the total eligible) of a meat packing plant were interviewed and examined. Non-participants were overrepresented by clerical workers (39\%). The rest of the non-participants were divided between supervisory staff $(50 \%)$ and maintenance staff $(11 \%)$. The demographics of the study population (table 2) include a male/female distribution of $86 / 14$ regardless of ethnicity. The ethnic distribution of the study population was predominantly Asian mixed (oriental) at 317 $(47.7 \%)$ with white second at $209(31.4 \%)$. Five hundred and twenty one employees (78.5\%) performed a job that required the use of a tool. It was not possible to stratify tool use among the employees because most tools, if used, were used often and very few were used seldom during a normal shift.

A case of CTS was defined by worker, not by hand. One hundred and forty cases of CTS were diagnosed for a prevalence of $21 \%$. Of those 140 cases, 93 involved the left hand, 92 the right hand, and 45 of the cases were bilateral. Sixty nine cases $(49.3 \%)$ were Asian mixed, whereas 47 cases $(33.6 \%)$ were white. The difference between Asian and white cases relative to their respective total ethnic populations is only $0.7 \%$ (table 3 ). No significant relation was found between ethnicity and prevalence of CTS $(p=0.43)$.

One hundred and nineteen (85\%) of the cases were men and $21(15 \%)$ were women. The average age of the 140 employees with CTS, independent of sex, was 31.5 years (range 18-51). The average BMI for workers with CTS was 23.7 (range 17-38) and for those workers without CTS it was 23 (range 16-35). Only three cases gave a history of comorbid conditions; two $(66.6 \%)$ reported arthritis and one $(33.3 \%)$ reported a thyroid disease. No association between prevalence of CTS and use of tools was found (table 4).

\section{INCIDENCE STUDY}

Four hundred and twenty one production workers without CTS were examined at a median interval of 253 days. Of these, 333 workers still remained negative and were again 
Table 4 Descriptive prevalence data for tool users and non-tool users

\begin{tabular}{|c|c|c|c|c|c|c|}
\hline \multirow[b]{2}{*}{ Tool use } & \multicolumn{5}{|c|}{ Prevalence of carpal tunnel syndrome } & \multirow[b]{2}{*}{$95 \% C I$} \\
\hline & Yes (n) & No (n) & Total (n) & & $e(\%)$ & \\
\hline & 113 & 408 & 521 & & & 18.2 to 25.5 \\
\hline No & 27 & 117 & 144 & & & 12.7 to 26.1 \\
\hline Total (n) & 140 & 525 & 665 & & & \\
\hline \multicolumn{7}{|c|}{$\begin{array}{l}\text { Estimated difference }(\mathrm{Y} / \mathrm{N})-2.94 \% ; 95 \% \text { confidence interval for difference }-10.2 \% \text { to } 4.35 \% \\
\text { Fisher's exact } 2 \text { sided test } \mathrm{p}=0.49 ; \text { uncorrected } \chi^{2} \text { test } \mathrm{p}=0.444 \text {. }\end{array}$} \\
\hline \multicolumn{7}{|l|}{ Table 5} \\
\hline & & Tool use & Not & & $I R R$ & $p$ Value \\
\hline \multicolumn{2}{|l|}{ Men } & 8.7 & 13.6 & & 0.64 & 0.25 \\
\hline \multicolumn{2}{|l|}{ Women } & 23.4 & 5.6 & & 4.2 & 0.14 \\
\hline \multicolumn{2}{|c|}{ Total population } & 10.8 & 12.0 & & 0.90 & 0.73 \\
\hline
\end{tabular}

examined at a median interval of 148 days. In this follow up population, $207(49.2 \%)$ were Asian mixed, 117 (27.8\%) were white, and 97 $(23.0 \%)$ were from another ethnic background (table 2). The male/female distribution of the incidence study population was $85: 15$. Three hundred and thirty two (78.9\%) employees performed a job that required the use of a tool. The crude risk incident rate ratio for tool use was 0.90 which was not significant $(p=0.73$, table 5). When tool use was added to the modelling for age, BMI, sex, and ethnicity, only sex and tool use were significant $(p=0.04)$. Although the effect of tool use varied between men and women and the incident rate ratio (IRR) was 4.2 for women, the numbers were small and not significant $(\mathrm{p}=0.14)$. The IRR for men who used tools was 0.64 but again any protective effect was not significant $(\mathrm{p}=0.25)$. A force model was not incorporated into this study.

Over 426 person-years of follow up, 47 cases of CTS were diagnosed at an incidence of $11 / 100$ person-years $(95 \%$ confidence interval (95\% CI) 8.3 to 14.7 ). One hundred and nineteen workers were lost to follow up in the first interval and 73 in the second. Characteristics of this group are presented in table 6. Twenty four cases involved the right hand alone, two involved the left hand only, and 21 cases were bilateral (at initial diagnosis).

Table 6 Workers lost to follow up in the incidence study

\begin{tabular}{llll}
\hline & Men & Women & Total \\
\hline $\begin{array}{llll}\text { Interval 1: } \\
\quad \text { White }\end{array}$ & 68 & 6 & 74 \\
$\quad$ Asian mixed & 40 & 5 & 45 \\
$\quad$ Total & 108 & 11 & 119 \\
Interval 2: & & & \\
$\quad$ White & 33 & 5 & 38 \\
$\quad$ Asian mixed & 30 & 5 & 35 \\
$\quad$ Total & 63 & 10 & 73 \\
\hline
\end{tabular}

Total workers lost to follow up $=192$.

Table 7 Crude and adjusted RRs contributing to developing carpal tunnel syndrome: incidence data

\begin{tabular}{lllllll}
\hline CTS & RR (crude) & $p$ Value & $95 \%$ CI & RR (adjusted) & $p$ Value & $95 \%$ CI \\
\hline Age $^{\star}$ & 1.304 & 0.134 & 0.921 to 1.847 & 1.025 & 0.187 & 0.988 to 1.0627 \\
Women & 1.901 & 0.055 & 0.987 to 3.663 & 1.88 & 0.061 & 0.972 to 3.648 \\
BMI & 1.006 & 0.888 & 0.921 to 1.099 & 1.016 & 0.748 & 0.922 to 1.119 \\
Asian mix & 1.246 & 0.453 & 0.7014 to 2.215 & 1.19 & 0.588 & 0.634 to 2.234 \\
\hline
\end{tabular}

^Age based on $10 \mathrm{y}$ increment.
Twenty six (55.3\%) of the cases were Asian mixed, $14(29.8 \%)$ white, and seven $(14.9 \%)$ of an other ethnicity. There were no significant ethnic differences in incidence $(p=0.40)$, which were $12.0,12.2$, and 7.2 cases/100 personyears, respectively (table 3). Thirty five $(74.5 \%)$ of the cases were men and $12(25.5 \%)$ were women. The median values of age and BMI of the cases were 33 (range 22-53) and 22.8 (range 17.2-31.2), respectively. The crude and adjusted relative risks accounting for age, sex, BMI, and ethnicity are presented in table 7. Three comorbid conditions were reported by the incidence cases; one pregnancy, one arthritis, and one thyroid disease.

\section{Discussion}

This study of predominantly production workers in a modern, line driven, automated meat processing plant showed a prevalence of CTS of $21 \%$ and an incidence of 11 cases/100 person years. The male/female ratio of disease in the prevalence data differed only slightly from the sex distribution in the study population by contrast with the higher prevalence of female cases in previous studies. Our incidence data showed that a higher percentage of women (25.5\%) developed CTS relative to their representation (15\%) within the study population, unrelated to age. There was a large relative risk (RR) for women that was of borderline significance.

The relative risk of CTS and tool use did not change if adjusted for age in either the prevalence or the incidence study. All workers who used tools did so at what would be considered high repetition according to the Silverstein formula of greater than one repetition per 30 seconds or continuous hand movement for over half of a task cycle. ${ }^{24}$ Further analysis of tool use found a significant sex effect and a high IRR for women but numbers of women were too few to establish significance. Female workers perform non-tool tasks in this industry that require less hand force than tool tasks. Use of a hook or knife involves very repetitive ( $>1$ repetition $/ 10 \mathrm{~s}$ ) forceful grasping, palmar compression, and awkward posturing which are all considered risk factors for the development of CTS. By contrast, non-tool jobs performed by men are generally heavier and may involve more forceful and prolonged (>5 s) grasping. For example, loading boxed meat up to $55 \mathrm{~kg}$ or grasping and folding wet hides may present an equal or greater risk than tool use for developing CTS in male workers. Further examination of these workers with an analogue force scale or a strain index would be necessary to evaluate the contribution of these job factors. ${ }^{25}$

There have been prevalence studies performed in related industries, but this is the first prospective study of incidence of work related CTS. We have attempted to improve the capture of symptomatic employees and reduce the effect of high worker turnover by staging two follow up assessments at intervals of less than 1 year. We think that this method is of value to others contemplating research on musculoskeletal injuries in industries with high worker turnover. 
Although more mixed Asian workers developed CTS, their numbers as a proportion of their ethnic population was similar to that of white people for both prevalence and incidence. This is by contrast with the experience of Nathan et al who compared CTS symptoms between Japanese and North American workers. ${ }^{22}$ The fact that 192 workers had left work, or were lost to follow up, might bias or underestimate the total number of cases of CTS. Thirty seven cases of CTS confirmed by electrophysiological study were diagnosed in the 3 years before the prevalence study with no cases involving clerical or supervisory personnel. The percentage of comorbid conditions was very small and probably represents a healthy applicant effect. It is probable that a healthy worker would apply in this labour intensive industry although it is possible that these workers did not wish to report any comorbid disease. Further investigation of these workers including appropriate laboratory testing may help to determine the true incidence of comorbid disease in this industry. Also, age and BMI were found to be unrelated to prevalence and incidence of CTS .

One of the benefits of the incidence data was to determine the number of potential compensation claims for CTS arising during employment. Electrophysiological studies were not included in our diagnostic criteria for the purpose of this study because all symptomatic cases have potential for generating compensation costs under the Provincial Act. Even a visit to a physician and job modifications without investigation results in compensation costs to the system. The provincial workers' compensation plan ensures the worker $90 \%$ of the wage before injury for time lost, and $100 \%$ if modified from regular duties; therefore, there is little disincentive to report. ${ }^{23}$

However, the lack of electrophysiological data for confirmation of a case limits the determination of sensitivity and specificity of the symptoms and signs. Median nerve symptoms and provocative testing has been shown to have diagnostic sensitivity of 0.29 , specificity of 0.83 , positive predictive value of 0.23 , and a negative predictive value of 0.87 in a study of non-hospital plant workers. ${ }^{26}$ It is not known what percentage of the cases of CTS found are sent for electrophysiological studies and surgery. Further study is required to determine those numbers and evaluate the effectiveness of job modifications and conservative treatments. It is possible that the incidence level determined in this study cannot be maintained annually because at some point the healthy worker effect must show itself. The healthy worker effect has been shown in a study by Baillargeon et al to be most evident in male workers over the age of 40 from high socioeconomic classes, however, non-white worker populations are an exception. ${ }^{27}$ This industry has shown that there is very little year to year variation in worker turnover. Wood et al reported a monthly turnover between $6 \%$ and $8 \%$ at a beef packing plant 7 years after it began operating. ${ }^{28}$ The plant under study has maintained a consistent $6 \%$ monthly worker turno- ver rate during and before this study. A study by Ohlsson et al found that $25 \%$ of workers who left their employment voluntarily did so because of upper limb pain. ${ }^{29}$

In summary, this modern meat packing plant was found to have a prevalence of CTS not higher than that reported for older multistoried plants. Also, we have determined an annual incidence of $11 / 100$ person-years by using a method whereby two follow up assessments were conducted at intervals of $<1$ year. Both the prevalence and the incidence of CTS in this plant are higher than that reported in the general working population. Age, BMI, comorbidity, and ethnicity seem to be unrelated to the incidence of CTS in this worker population. Tool use by women was associated with an increased incidence of CTS in this industrial population. Further analysis of the grasping forces in jobs that do not use tools is required and would lead to a better understanding of their contribution to the higher incidence of CTS in this worker population. If the strain index of Moore and Garg were applied to tasks within the meat packing industry, we think that they would be greater than those performed by the general working population, and thus deserves further investigation..$^{25}$

This study was supported by the Workers' Compensation Board of Alberta and Cargill Foods

1 Ectasia. Dorland's illustrated medical dictionary, 27th ed. Philadelphia: Saunders, 1988.

2 Stevens JC. AAEE minimonograph 26: the electrodiagnosis of carpal tunnel syndrome. Muscle Nerve 1987;10:99nosis 113.

3 Campion D. Electrodiagnostic testing in hand surgery. $f$ Hand Surg Am 1996;21:947-56.

4 de Krom M, Knipschild P, Kester A, et al. CTS: prevalence in the general population. F Clin Epidemiol 1992;45:373-6.

5 Stevens JC, Sun S, Beard CM, et al. Carpal tunnel syndrome in Rochester Minnesota, 1961-80. Neurology 1988;38:1348.

6 Rossignol M, Stock S, Patry L, et al. Carpal tunnel syndrome: what is attributable to work? The Montreal study. Occup Environ Med 1997;54:519-23.

7 Liss G, Armstrong C, Kusiak R, et al. Use of provincial health insurance plan billing data to estimate carpal tunnel syndrome morbidity and surgery rates. Am f Ind Med 1992;22:395-409.

8 Masear VR, Hayes JM, Hyde AG. An industrial cause of carpal tunnel syndrome. F Hand Surg Am 1986;11:222-

9 Moore SJ, Garg A. Upper extremity disorders in a pork processing plant: relationships between job risk factors and morbidity. Am Ind Hyg Assoc F 1994;55:703-15.

10 Kaplan SJ, Glickel SZ, Eaton RG. Predictive factors in the non-surgical treatment of carpal tunnel syndrome. 7 Hand Surg 1990;15B:106-8.

11 Kurppa K, Viikari-Juntura E, Kuosma E, et al. Incidence of tenosynovitis or peritendinitis and epicondylitis in a meatprocessing factory. Scand 7 Work Environ Health 1991;17: 32-7.

12 Novek, J. The labour process and workplace injuries in the Canadian meat packing industry. Canadian Reviews in Sociology and Anthropology 1992;29:17-38.

13 Hadler NM. Arm pain in the workplace: a small area analysis. F Occup Med 1992;34:113-19.

14 Nathan P, Meadows K, Doyle L. Relationship of age and sex to sensory conduction of the median nerve at the carpal tunnel and association of slowed conduction with symptoms. Muscle Nerve 1988;11:1149-53.

15 Armstrong TJ, Fine L, Goldstein S, et al. Ergonomics considerations in hand and wrist tendonitis. $\mathcal{F}$ Hand Surg Am 1987;12:830-7.

16 European Commission Health and Safety Bulletin. Information notices on diagnosis of occupational disease [report]. Brussels: EEC, 1994:160.

17 The United Kingdom Industrial Injuries Advisory Council Department of Social Security. Notes on the diagnosis of pre-
scribed diseases: disease A12, carpal tunnel syndrome [report]. scribed diseases: disease A12,

18 Diwalker HN, Stothard J. What do doctors mean by tenosynovitis and repetitive strain injury. Occup Med 1995; 45:97-104. 
19 Barnhart S, Demer P, Miller M, et al. Carpal tunnel syndrome among ski manufacturing workers. Scand $\mathcal{f}$ Work Enndrome among ski manufact

20 Katz JN, Larson MG, Fossel AH, et al. Validation of a surveillance case definition of carpal tunnel syndrome. Am $\mathcal{F}$ Public Health 1991;81:189-93.

21 Gorsche, RG. A butcher with sharp pains in his arms. Lancet 1996;348:862.

22 Nathan P, Takigawa K, Keniston R, et al. Slowing of sensory conduction of the median nerve and CTS in Japanese and American industrial workers. F Hand Surg Br 1994;19:304.

23 Workers' Compensation Board. Provincial statistics for carpal tunnel syndrome 1990-5. Edmonton, Alberta: Finance/ Actuarial Services, 1995.

24 Silverstein BA, Fine LS, Armstrong TJ. Occupational factors and carpal tunnel syndrome. Am $\mathcal{f}$ Ind $M e d$ 1987;11:343-58.
25 Moore SJ, Garg A. The strain index: a proposed method to analyze jobs for risk of distal upper extremity disorders. $A m$ Ind Hyg Assoc f 1995;56:443-58.

26 Franzblau A, Werner R, Valle J, et al. Workplace surveillance for carpal tunnel syndrome: a comparison of methods. Fournal of Occupational Rehabilitation 1993;3:1-13.

27 Baillargeon J, Wilkinson G, Rudkin L, et al. Characteristics of the healthy worker effect: a comparison of male and female occupational cohorts. $f$ Occup Environ Med 1998;40:368-73.

28 Wood A. The beef packing industry: a study of three communities in southwestern Kansas. Final Report to the Department of Migrant Education. Falgstaff, AZ: Wood and Wood Associates, 1988.

29 Ohlsson K, Hansson GA, Balogh I, et al. Disorders of the neck and upper limb in women in the fish processing industry. Occup Med 1994;51:826-32.

\section{Vancouver style}

All manuscripts submitted to Occup Environ Med should conform to the uniform requirements for manuscripts submitted to biomedical journals (known as the Vancouver style.)

Occup Environ Med, together with many other international biomedical journals, has agreed to accept articles prepared in accordance with the Vancouver style. The style (described in full in the $\mathcal{F} A M A[1]$ ) is intended to standardise requirements for authors, and is the same as in this issue.

References should be numbered consecutively in the order in which they are first mentioned in the text by Arabic numerals on the line in square brackets on each occasion the reference is cited (Manson[1] confirmed other reports[2][3][4][5]). In future references to papers submitted to Occup Environ Med should include: the names of all authors if there are three or less or, if there are more, the first three followed by et al; the title of journal articles or book chapters; the titles of journals abbreviated according to the style of Index Medicus; and the first and final page numbers of the article or chapter. Titles not in Index Medicus should be given in full.

Examples of common forms of references are:

1 International Committee of Medical Journal Editors. Uniform requirements for manuscripts submitted to biomed journals. $7 A M A$ 1993;269:2282-6.

2 Soter NA, Wasserman SI, Austen KF. Cold urticaria: release into the circulation of histmaine and eosinophil chemotactic factor of anaphylaxis during cold challenge. N Engl F Med 1976;294:687-90.

3 Weinstein L, Swartz MN. Pathogenic properties of invading micro-organisms. In: Sodeman WA Jr, Sodeman WA, eds. Pathologic physiology, mechanisms of disease. Philadelphia: W B Saunders, 1974:457-72. 